\title{
Materiais educativos impressos sobre saúde sexual e reprodutiva utilizados na atenção básica em Belo Horizonte, MG: caracterização e algumas considerações ${ }^{1}$
}

DOI: 10.3395/reciis.v3i4.149pt

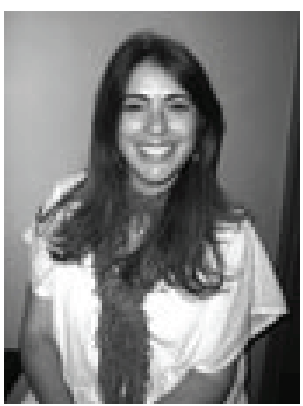

Maria José Nogueira

Instituto René-Rachou - Fiocruz, Belo Horizonte, Brasil maria.nog@cpqrr.fiocruz.br

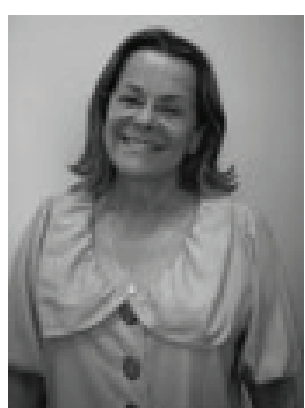

Celina Maria

Modena

Instituto René-Rachou

- Fiocruz, Belo

Horizonte, Brasil

celina@cpqrr.fiocruz.br

\section{Virginia Torres Schall}

Instituto René-Rachou - Fiocruz, Belo Horizonte, Brasil

vtschall@cpqrr.fiocruz.br

\section{Resumo}

Realizou-se uma análise inicial de materiais educativos impressos utilizados pela Secretaria Municipal de Saúde (SMS) de Belo Horizonte $(\mathrm{BH})$ sobre temas ligados à saúde sexual e reprodutiva. Foram considerados como pressupostos que a educação em saúde é uma prática que se desenvolve ao nível das relações sociais e que os meios de comunicação de massa e as interações cotidianas podem ser elos entre a população e os serviços de saúde. A partir da coleta de materiais impressos em uma Unidade Básica de Saúde (UBS) da SMS/BH, foi realizada classificação, descrição e análise de conteúdo e ilustração dos mesmos. Para contemplar os significados atribuídos às dimensões sexuais e reprodutivas do corpo pelos adolescentes, mediados por um dos materiais, utilizou-se um grupo focal. Com os profissionais de saúde foram realizadas entrevistas semi- estruturadas. Destaca-se que os materiais são produzidos de forma vertical, tratando o público alvo como algo estanque e homogêneo, prevalecendo a temática DST/AIDS. Alguns dos materiais que focalizam a aids demonstram boa qualidade, apresentando uma linguagem objetiva, clara e ilustrações pertinentes. Contudo, na maioria, prevalece a abordagem da dimensão do corpo biomédico em detrimento de uma abordagem mais ampla da sexualidade. Fazem-se necessários avaliações e estudos de recepção para que a produção de material educativo esteja associada ao contexto existencial do público a que é direcionado e que critérios de qualidade dos mesmos estejam incluídos na formação dos profissionais de saúde.

\section{Palavras-chave}

materiais educativos; saúde sexual; saúde reprodutiva; adolescentes 


\section{Introdução}

O presente artigo apresenta uma análise descritiva e considerações críticas sobre os materiais educativos impressos utilizados pela Secretaria Municipal de Saúde de Belo Horizonte/MG (SMS/ $\mathrm{BH})$ relativos a temas ligados à saúde sexual e reprodutiva bem como a avaliação da recepção dos adolescentes de um material específico: o Álbum Seriado sobre Doenças Sexualmente Transmissíveis (DST); (MINISTÉRIO DA SAÚDE， s/data); (Figura 1).

Para análise dos materiais educativos parte-se do pressuposto que a educação em saúde é acima de tudo educação. Privilegia-se assim uma concepção de educação dialógica destinada não só a comunicar conhecimentos, mas a desenvolver e modificar atitudes (FREIRE, 1987). Uma educação em saúde que traz para o campo da educação a importância da interação dos saberes, da prática cotidiana, das representações sociais e da afetividade, em detrimento de uma perspectiva de educação pautada meramente no aspecto cognitivo (SCHALL, 1996).

A educação em saúde pode ser concebida como o campo de práticas que se dão no nível das relações sociais (L'ABBATE, 1994) e os meios de comunicação de massa e as interações cotidianas são as formas de ligação entre a população e os serviços de saúde (VASCONCELOS, 1999). Nessa perspectiva, vídeos, folhetos, panfletos, cartilhas, dentre outros, são valiosos instrumentos no campo da educação em saúde pelo caráter informativo dos mesmos. Mas não se pode tomar como verdadeira e linear a suposição de que mais informação é igual a mais autonomia, uma vez que os sujeitos estão imersos em uma complexa rede de relações sociais e seus comportamentos e suas práticas cotidianas não são guiados por uma única racionalidade. No âmbito da comunicação estabelece-se um diálogo com o paradigma das interações comunicacionais, no qual se evidencia a tentativa de superar o caráter restritivo e formalizador que a noção de comunicação adquiriu com a utilização do paradigma clássico que postulava uma noção de comunicação a partir de uma forma fixa, rígida, de identificação e de delimitação de seus elementos internos.

No paradigma praxiológico, ao reconhecer a importância da construção compartilhada, Querè (1991) evidencia o caráter dialógico em oposição ao caráter monológico, que não se adequa, para explicar o processo comunicativo. A idéia de produzir representações similares, junto ao comunicador e seu destinatário, é restrita; é preciso compartilhar para interagir. Nesse momento, o papel do outro passa a ser fundamental. Para o modelo praxiológico não mais existe o mundo prédefinido, passível de representação. Ao contrário, a determinação só é possível a partir de uma ação comunicativa construída na relação com o outro.

No que se refere à ancoragem dos modelos de comunicação dos projetos educativos na área da saúde, segundo Meyer et al. (2006), os mesmos, em sua maioria, estão inscritos na ótica de transmissão de conhecimento especializado, estritamente relacionados com as práticas sanitaristas hegemônicas ao longo do século XX, pautadas na universalidade, na objetividade e na neutralidade do conhecimento científico.

$\mathrm{Na}$ mesma vertente, Vasconcellos-Silva et al. (2003, p. 538) apontam que os folhetos informativos utilizados no ambiente hospitalar têm sido produzidos e veiculados de maneira instrumental $e$ monológica, para transmitir informações unilateralmente definidas como relevantes e sem estudos de recepção posterior. A discussão acerca da não linearidade entre informação e mudanças de comportamento aparece de forma recorrente em vários estudos no campo da antropologia, sociologia e psicologia (VARGAS \& SIQUEIRA, 1999; ROZEMBERG et al., 2002; MONTEIRO \& VARGAS, 2006).

No caso específico do comportamento sexual, o fenômeno denominado Know-do gap (WHO, 2008) pode ser percebido nas pesquisas que apontam que os adolescentes têm conhecimento acerca dos métodos contraceptivos e, em muitos casos, sabem como utilizá-los, mas este conhecimento não se traduz em uso efetivo, uma vez que as DST - principalmente HIV - e a gravidez têm aumentado na faixa etária de 10 a 19 anos (IBGE, 2004; SINASC, 2004; NOGUEIRA et al., 2009). Desse modo, o acesso à informação é necessário, mas não suficiente para colocar o conhecimento em prática. A informação científica é um dado fundamental para o desenvolvimento de atitudes preventivas, mas não o suficiente para mudar comportamentos de risco (ABDUCH, 1999).

A consideração de fatores subjetivos, bem como a incorporação de variáveis externas, por meio do reconhecimento do contexto sócio-cultural possibilita compreender melhor a lacuna entre conhecimento-informação e uso, prática ou adoção. Segundo Vargas e Siqueira (1999), a produção de materiais educativos deve estar pautada na premissa de um receptor ativo, uma vez que, ao receber uma mensagem o indivíduo irá interpretar e ressignificar o seu conteúdo de acordo com seu lugar na sociedade. Em avaliação de vídeos educativos no campo da sexualidade, junto a profissionais de saúde, aponta- 
se que aqueles podem estar cumprindo uma função de ilustração dos discursos que informam as práticas no campo da saúde, em detrimento da exploração do imaginário social que perpassa, de forma diferenciada, o comportamento preventivo dos sujeitos pertencentes a grupos culturalmente definidos. Deve-se pensar em práticas de promoção da saúde mais criativas e horizontais bem como na utilização de materiais educativos de forma menos instrumental. Como salienta Villa (2006, p. 47).

O educar na prática da saúde não se limita à absorção passiva de informações padronizadas, mas à possibilidade de libertação do espaço e do tempo presentes, de fazer relações mentais diferentes, imaginar, fazer planos, transformar, tomar posse do próprio fazer/saber.

Diante da importância dos materiais educativos nos processos pedagógicos que visam à promoção da saúde junto ao público adolescente, propõe-se a análise de alguns materiais impressos utilizados na rede de atenção básica do município de Belo Horizonte sobre temas ligados à saúde sexual e reprodutiva. Desse modo, com base na coleta e análise dos materiais impressos, na interlocução com gerentes de atenção à saúde e na opinião de um grupo de adolescentes discutese a qualidade, a pertinência e a adequação dos mesmos aos processos educativos em saúde.

\section{Metodologia}

\section{Seleção dos materiais}

Os materiais educativos impressos relacionados à saúde sexual e reprodutiva foram coletados, principalmente, na Unidade Básica de Saúde (UBS) Cafezal, pertencente à Regional de Saúde Centro Sul de Belo Horizonte. A escolha deveu-se a critérios epidemiológicos encontrados em estudo de georreferenciamento dos nascidos vivos no município de Belo Horizonte (NOGUEIRA, 2008) que correlacionou a gravidez na adolescência com aspectos socioeconômicos e de vulnerabilidade social. Os dados revelam uma alta incidência de gravidez na adolescência na região na qual esta inserida a vila Cafezal (NOGUEIRA et al., 2009).

Desse modo, solicitou-se à gerência da UBS que fornecesse todos os materiais disponíveis que tinham sido enviados pela SMS para ações e estratégias educativas que contemplassem temáticas ligadas à saúde sexual e reprodutiva como planejamento familiar, uso de preservativo, gravidez, dentre outras.

Embora a coleta tenha sido feita em uma unidade especifica o material é significativo, pois é distribuído pela SMS/-BH para todas as UBS. A seleção seguiu o critério de trabalhar com materiais que fossem utilizados fora dos períodos específicos como carnaval ou dia mundial de luta contra aids. A Tabela mostra a relação dos materiais educativos selecionados e organizados por tipo, tema, órgão e modalidade.

\section{Tabela - Relação de materiais educativos utilizados em unidades básicas de saúde de Belo Horizonte, MG - Seleção e organização por tipo}

\begin{tabular}{|c|c|c|c|}
\hline Material & Tema & Órgão & Modalidade \\
\hline Álbum Seriado & DST/AIDS & $M S$ - GF & AS \\
\hline Camisinha: todo mundo usa & DST/AIDS & PBH - MS & CA \\
\hline Sem camisinha, nem pensar & DST/AIDS & MS - GF & CA \\
\hline Aprenda a se defender & DST/AIDS & $\mathrm{PBH}-\mathrm{MS}$ & FO \\
\hline Quem sabe se um de nós & DST/AIDS & PBH - MS & FO \\
\hline Atenção à mulher & $\begin{array}{l}\text { Planejamento } \\
\text { familiar }\end{array}$ & PBH - MS & FO \\
\hline Aquele sexo básico & DST/AIDS & PBH - MS & FO \\
\hline Pai tem que dar o exemplo & DST/AIDS & MS - GEMG & PA \\
\hline Basta uma vez & DST/AIDS & PBH - MS & PA \\
\hline No jogo da vida, vista acamisa... & DST/AIDS & PBH - MS & PA \\
\hline Transa arriscada & DST/AIDS & PBH - MS & PA \\
\hline Na hora H... & DST/AIDS & MS - GF & PA \\
\hline Não saio sem ela & DST/AIDS & MS - GF & PA \\
\hline Na roça ou na cidade & DST/AIDS & MS - GF & PA \\
\hline Te espero na saída & DST/AIDS & $M S-G F$ & PA \\
\hline
\end{tabular}

(CA) cartaz; (FO) folheto; (PA) panfleto; (AS) álbum seriado; (PBH) Prefeitura de Belo Horizonte; (MS) Ministério da Saúde; (GF) Governo Federal; (GEMG) Governo Estadual de Minas Gerais. 


\section{Procedimento metodológico}

O material foi primeiramente classificado da seguinte forma: (CA) cartaz; (FO) folheto; (PA) panfleto; (AS) álbum seriado. A seguir, realizou-se uma análise da estrutura observando os itens: indicação textual do público alvo, local e data, órgão responsável pela publicação e foco.

Paralelamente foram realizadas entrevistas semiestruturadas dirigidas a informantes chaves em cada um dos nove distritos sanitários do município. No roteiro semiestruturado um dos temas abordados foi o uso de materiais educativos nas ações educativas nas UBS. Como o AS foi bastante citado nas entrevistas, apontando posturas divergentes quanto à qualidade e eficácia do mesmo, optou-se em analisar como esse material dialoga com o público adolescente. Desse modo, segundo metodologia proposta por Débus (1994), realizou-se um grupo focal com roteiro semiestruturado nas seguintes temáticas: conhecimento do álbum, ilustrações e conteúdo. Participaram nove adolescentes, um agente comunitário de saúde, uma enfermeira e o coordenador.

As entrevistas com o grupo focal foram gravadas e o conteúdo foi transcrito. Os dados foram analisados na perspectiva da análise de conteúdo de Bardin (1977) que se baseia em operações de desmembramento do texto em unidades, ou seja, descobrir os diferentes núcleos de sentido que constituem a comunicação e, posteriormente, realizar o seu reagrupamento em classes ou categorias. Realizaram-se as seguintes etapas: leitura flutuante, categorização e análise das categorias.

\section{Resultados e discussão \\ Materiais educativos: conteúdo, linguagem e estrutura}

O AS contém seis painéis com informações acerca das principais DST acompanhadas de ilustrações coloridas (Figura 1), um painel com instruções para o uso correto do preservativo masculino e um painel com dicas de prevenção.

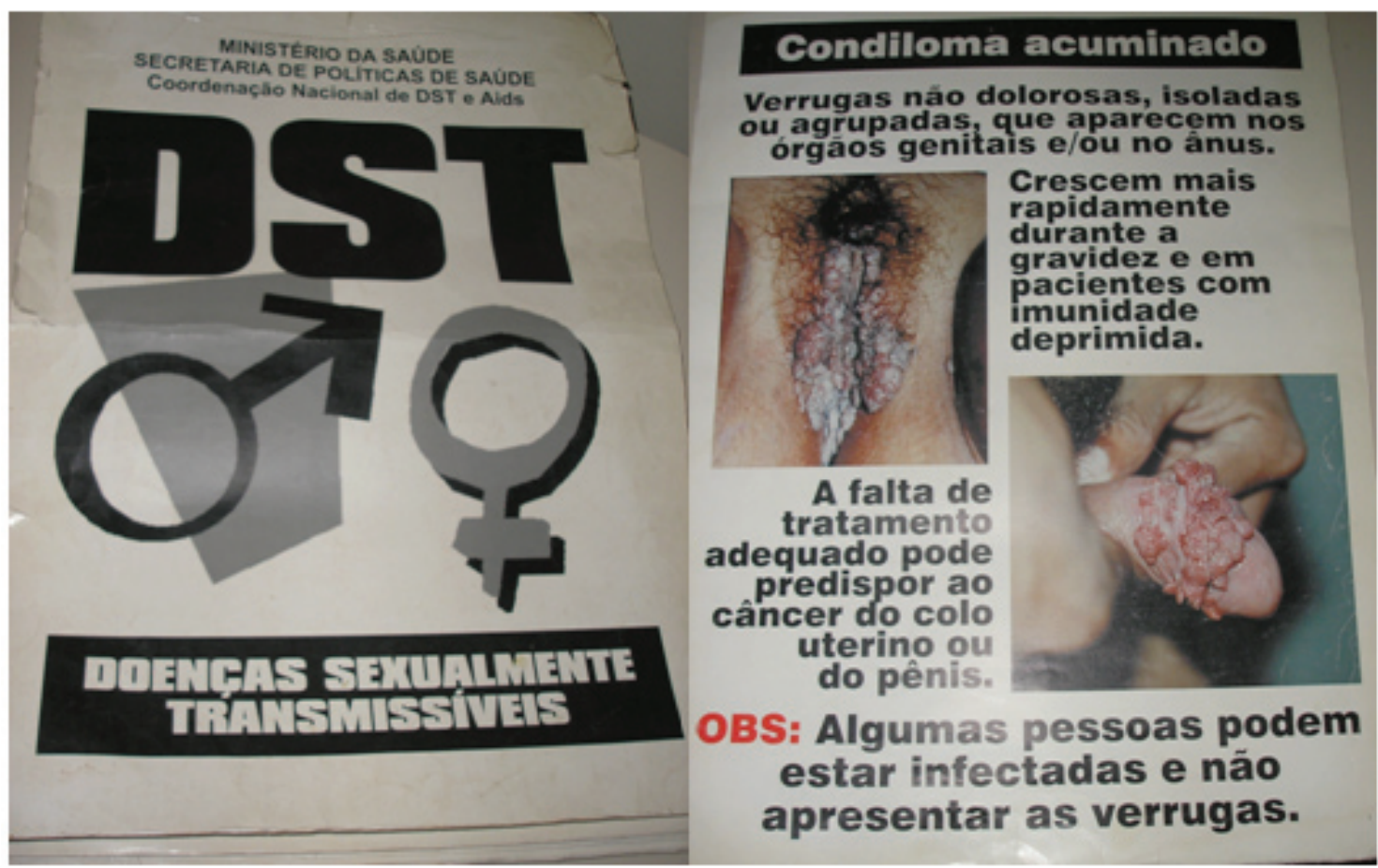

Figura 1 - Álbum Seriado sobre doenças sexualmente transmissíveis utilizados nas unidades básicas de saúde de Belo Horizonte.

Fonte: Ministério da Saúde, sem data. 
Os dois cartazes (números 2 e 3 , Tabela 1 ) trazem mensagem alusivas ao uso de preservativos. No cartaz número 2 o enunciado "camisinha: todo mundo usa" está associado às imagens que fazem alusão à diversidade em termos de gênero, etnia/ raça e explicita também a singularidade dos sujeitos pelos adereços como bonés, cabelos coloridos, tipo de óculos (Figuras 2 e 3). Busca-se desse modo disassociar a imagem recorrente do uso da camisinha a um público específico.

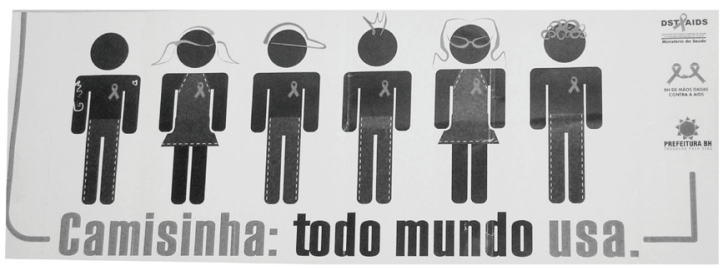

Figura 2 - Cartaz sobre doenças sexualmente transmissíveis produzido pela Prefeitura Municipal de Belo Horizonte em parceria com o Ministério da Saúde.

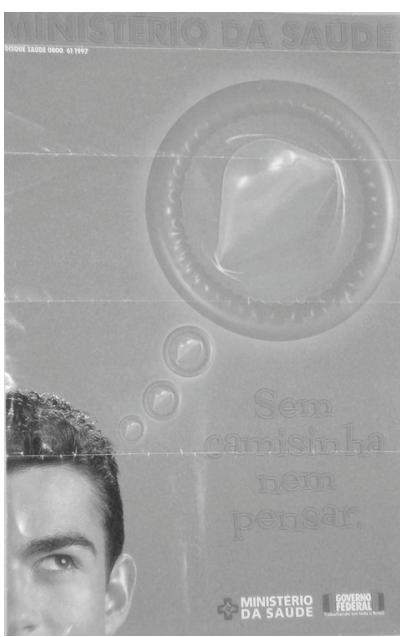

Figura 3 - Cartaz sobre doenças sexualmente transmissíveis produzido pelo Ministério da Saúde.

As mensagens são diretas como: "Camisinha todo mundo usa" e "Sem camisinha nem pensar". Dos quatro folhetos, dois são direcionados para o uso do preservativo (números 5 e 7 ) com ilustrações simples. Apresentam passo a passo as instruções para o uso adequado do preservativo feminino e masculino. Os outros dois (números 4 e 6, Tabela 1) contêm abordagens distintas. O número 4 destina-se a informações gerais das DST, incluindo dicas de prevenção, tratamento e fornece o endereço de Organizações Não-Governamentais (ONG), ambulatórios, grupos de apoio e do Centro de Orientação e Apoio Sorológico (COAS-BH), atualmente conhecido como Centro de Testagem e Aconselhamento (CTA-BH). Apresenta também dicas para negociação do uso do preservativo, contemplando assim as relações de gênero implicadas no uso de medidas contraceptivas.

Aponta-se que um material com muito texto será pouco atrativo para o público adolescente que normalmente tem o pouco hábito da leitura, estando geralmente cumprindo exigências escolares (SANTOS, 1993).

O número 6 é o único material que contempla uma abordagem mais ampla da sexualidade direcionada ao gênero feminino (Figura $4)$.

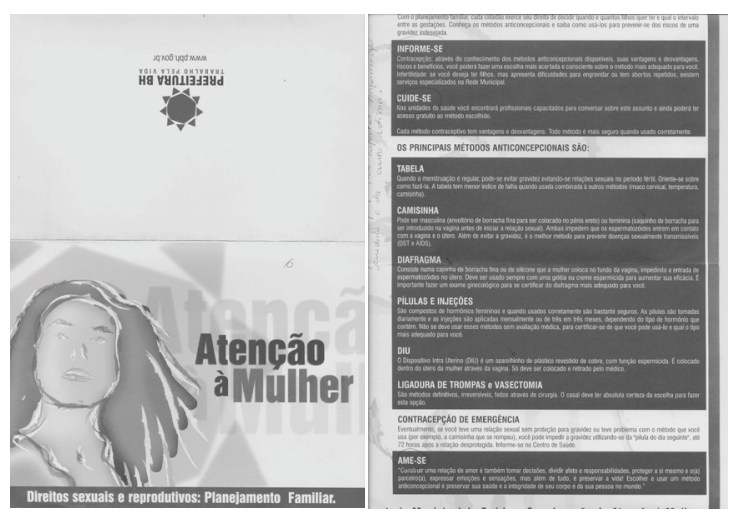

Figura 4 - Álbum "Atenção à Mulher", voltado para o planejamento familiar, produzido pela Prefeitura Municipal de Belo Horizonte em parceria com o Ministério da Saúde.

Aborda a temática do planejamento familiar com ênfase nos direitos sexuais e reprodutivos da mulher. Descreve os diversos métodos anticoncepcionais abordando a forma de uso. Através das expressões: "cuide-se”, "informese" e "ame-se" são abordados de forma direta os aspectos do cuidado, da informação e da autoestima, alertando para a necessidade de o sujeito apropriarse do seu corpo em todas as dimensões.

Dos oito panfletos (PA números 8 a 15, Tabela 1) os quatro últimos (números 12 a 15) fazem parte de uma série em forma de cartão postal com imagens associadas aos enunciados (Figura 5). É uma forma criativa de associar os preservativos aos eventos cotidianos como trabalho, lazer e locais diversos. As mensagens no verso visam a familiarizar 

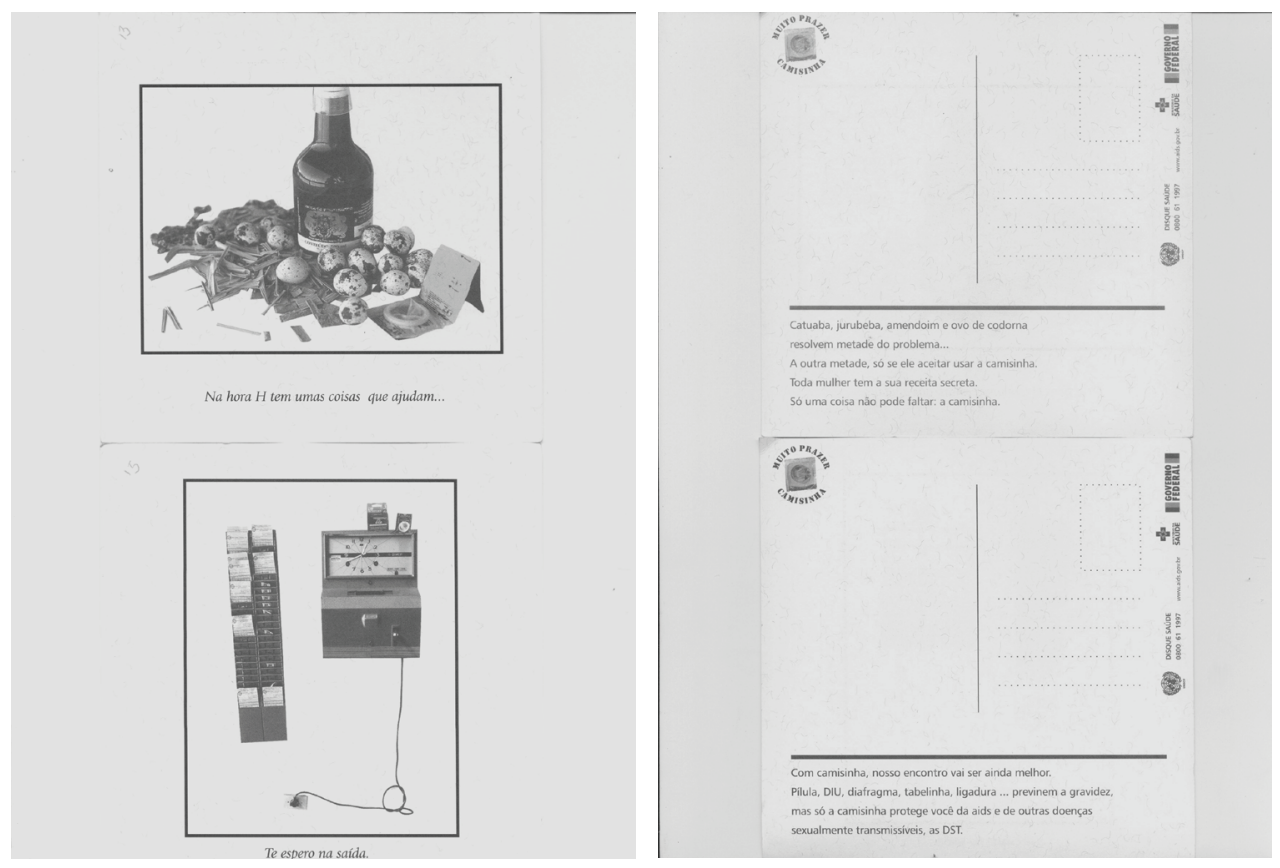

Figura 5 - Série Postais "Muito prazer Camisinha", produzido pelo Ministério da Saúde.

o uso do preservativo como elemento a ser inserido na vida cotidiana associado ao prazer e à prevenção sem preconceitos.

Quanto aos PA números 8 e 10 embora não tragam textualmente o público alvo, supõese que estejam dirigidos ao público masculino, considerando as imagens (jogadores de times mineiros ) e a frase: "Pai tem que dar o exemplo".

Os PA de números 9, 10 e 11 , têm mensagens semelhantes: "assim pega" e "assim não pega” aids. A linguagem escrita não traz a relação direta do preservativo com o texto, cabendo ao leitor fazer a associação. Por exemplo, ao dizer que pega "através de sexo oral (boca/pênis, boca/ vagina, boca/ânus) e sexo vaginal (pênis/vagina)" não é explicitado que tais ações, se realizadas com o preservativo, deixam de apresentar risco. A doação de sangue é enfatizada no "assim não pega" sem informar que deve ser realizada com material descartável.

Um ponto a ser destacado na avaliação do material é que os mesmos não explicitam textualmente o público alvo adolescente, com exceção do folder de planejamento familiar que, além de ser o único no tema, é voltado à saúde da mulher especificamente. Esta generalização do público alvo está associada a uma lógica do modelo linear de comunicação (FAUSTO-NETO, 1995) que inclui: ênfase no caráter instrumental do processo comunicativo, no qual o pólo receptor é considerado uma "massa amorfa", desconsidera-se a heterogeneidade dos indivíduos em seus atributos (físicos, biológicos e cognitivos). De acordo com Rozemberg et al. (2002, p. 1693),

Parece não existir ainda um reconhecimento formal, por parte das instituições, de que, apesar de se ocuparem aparentemente da mesma temática, profissionais e clientela são núcleos discursivamente distintos, elaborando significados segundo experiências e mundos identitários próprios.

Pode-se verificar uma tendência a aproximar os indivíduos em suas generalizações e não em suas especificidades, o que remete à noção de público elástico, em última instância, diretamente correlacionada à preocupação distributiva por parte do pólo emissor (FAUSTO-NETO, 1995). A lógica de não segmentação da audiência e a tendência distributiva são características marcantes nas Campanhas de Saúde Pública (KELLEY-SANTOS \& ROZEMBERG, 2005). Tais características foram evidenciadas, também, em outros estudos (ROZEMBERG et al. 2002; VASCONCELOSSILVA et al. 2003; LUZ et al. 2003; PIMENTA et al. 2007).

A predominância da temática da DST/ AIDS foi recorrente nos materiais analisados. 
Evidencia-se em mais de 90\% dos mesmos, uma tendência a ancorar as práticas discursivas na dimensão reprodutiva do corpo, em detrimento da dimensão sexual. Vargas e Siqueira (1999) argumentam que é preciso ampliar a visão sob o corpo e sexualidade considerando os condicionantes socioculturais implicados nos modos de homens e mulheres vivenciarem a sexualidade. Segundo Costa (1996) esta é uma questão central na constituição dos sujeitos e das identidades sociais.

Deve-se considerar que em um momento histórico de aumento das taxas de disseminação de doenças pela via sexual, principalmente entre jovens e mulheres, as instâncias públicas não podem e não devem se furtar do papel preventivo a elas atribuído, no sentido de informar à população a respeito das formas de contaminação, riscos, aspectos preventivos, tratamento etc. Por outro lado, as temáticas mais amplas que envolvem a saúde sexual e reprodutiva também devem ser contempladas: a sexualidade como direito de homens e mulheres; as relações de gênero implicadas no uso e negociações de medidas contraceptivas; a gravidez na adolescência; as relações familiares. Tal fato já foi apontado pela pesquisa do "Projeto Prisma" do Núcleo de Estudos da Saúde do Adolescente - Nessa/Uerj (BARROS et al.1999).

\section{Materiais educativos: o que os gerentes têm a dizer?}

Os gerentes entrevistados apontam para a necessidade de um material que reflita os desejos e as preocupações dos próprios adolescentes. Destacam que ainda são tímidas as iniciativas de produção de materiais nas próprias UBS.

(...) Acho que, talvez, a gente poderia juntar esses adolescentes e perguntar pra eles o tipo de material ou confeccionar com eles o tipo de material que fosse mais adequado... Tem uma boneca que a gente recebeu um tempo atrás... Ela chama Gertrudes... Aquele eu acho mais simpático, que ele permite uma interação maior das pessoas com o material educativo e ele não é... caricato... ele não é... ele é real... o corpo masculino... o corpo feminino... $e$ as pessoas trabalham em cima daquilo.

(Gerente - Distrito Sanitário)

Nogueira (2008) ao realizar um levantamento das estratégias e materiais educativos voltados para os adolescentes, no que se refere às temáticas da saúde sexual e reprodutiva, verificou que o AS (Figura 1) é bastante utilizado nas estratégias educativas na atenção básica. $\mathrm{O}$ álbum traz imagens explícitas de quadros avançados de doenças sexualmente transmissíveis. Algumas falas apontam para o ponto de vista dos entrevistados acerca da qualidade atribuída a este material.

O álbum seriado das DST é muito impressionante, eles fizeram umas gravuras muito impressionantes das DST, muito feias. Então eles ficam chocados, eles voltam, querem ver de novo. Então a gente vê que o visual faz impacto. Eu acho que é um elemento muito bacana de trabalha.

(Gerente - Distrito Sanitário 03).

Percebe-se que o entrevistado possui uma visão positiva acerca da utilização de imagens grotescas e exageradas nos materiais educativos. Em outra perspectiva, percebe-se uma avaliação negativa:

Aquele álbum seriado de DST/AIDS, onde mostra as doenças, é algo que adolescente não fica muito seduzido por aquilo não... Eu acho que é uma coisa que intimida, mas não educa

(Gerente - Distrito Sanitário I).

As falas expressam alguns aspectos que estão presentes na literatura referente a materiais educativos na área de saúde. Pimenta et al. (2007) destacam que na elaboração de estratégias educativas na área de saúde é recorrente a utilização de recursos de imagens grotescas e exageradas da doença.

Em suas análises, Luz et al. (2003) revelam que as formas de significação e utilização da imagem em materiais impressos sobre leishmaniose reduzem o portador ao mero status de doente. As imagens sobre as consequências físicas da doença são, muitas vezes, utilizadas como recurso de alerta à população. A mensagem veiculada alerta a população quanto à necessidade de se cuidar, “senão você poderá ficar assim”. Tal fato está presente nos materiais educativos para prevenção das DST (Figura 1) prevalecendo a utilização de recursos de espetacularização e sensacionalismo da doença, comumente utilizados nas campanhas e nos materiais educativos em saúde (LUZ et al. 2003; PIMENTA et al. 2007).

Esta contradição na percepção do caráter educativo do AS alerta para a necessidade da avaliação do mesmo, no sentido de analisar o seu potencial educativo. Alerta também para a consideração dos critérios de desenvolvimento e avaliação na formação de profissionais de saúde. Percebe-se que há visões díspares sobre o mesmo material, com base em aspectos subjetivos por falta de conhecimento dos parâmetros que norteiam a qualidade e eficácia dos materiais educativos.

Se aos profissionais de saúde faltam 
parâmetros de qualidade dos materiais disponibilizados, alguns autores apontam para a necessidade de estudos mais sistematizados de recepção de mensagens junto ao público alvo. Monteiro e Vargas (2006) destacam a necessidade de uma reflexão conceitual sobre a utilização dos chamados materiais educativos na área da saúde, visto que o desenvolvimento e o uso de tais recursos encontram-se sempre apoiados em um determinado referencial teórico educacional, nem sempre explicitado. $\mathrm{O}$ uso de recursos educativos e suas relações com as concepções educativas preventivas estão mais inseridos em contextos de intervenção educativa do que de reflexão acadêmica. As implicações da falta de articulação entre uma sistematização teórico-metodológica e os chamados materiais educativos usados como suporte das ações pedagógicas foram também evidenciadas por Vargas e Siqueira (1999).

\section{Materiais educativos: o que os adolescentes têm a dizer?}

A partir da exposição do AS no grupo focal com os jovens, inaugurou-se um processo discursivo marcado por expressões de esquiva como: "credo!", "isso é feio", "é esquisito", "tem que tampar o rosto"; "perereca cabeluda"; "tira isso daí".

Ao ver a imagem de um pênis com herpes genital, um adolescente foi bastante categórico: “tem que castrar ele". Tal fala poderia apontar para uma associação bastante fatalista que o mesmo atribuiu ao quadro apresentado da doença. $\mathrm{Na}$ perspectiva do feminino, a imagem de uma vagina com DST remeteu ao seguinte relato: "parece carne moída!", "quando você for comer carne moída vai lembrar do que você falou!"

A reação dos adolescentes às imagens do AS, traduzidas pelas expressões citadas e pelos gestos de tapar os olhos e virar o rosto, apontam para a necessidade de refletir acerca da utilização da estética do grotesco e da espetacularização das imagens de doenças, tão recorrentes em materiais educativos na área de saúde, já problematizada por Pimenta et al. (2007) e por Luz et al. (2003).

Referente às demandas na área de saúde, Ayres (2002) destaca que a interpretação das mesmas em sua dimensão sociocultural é condição necessária para que as ações e estratégias no campo da saúde possam ser adequadas ao público alvo. $\mathrm{O}$ autor chama atenção para um novo desenho no campo da saúde que busca a partir de identidades subjetivas - mulheres, idosos e adolescentes elaborar os programas e as ações educativas. Quando demandados, os adolescentes opinam sobre os materiais que poderiam ser mais motivadores:
“Mas tipo... Palavras... Ensinava assim ó: o negócio é assim e tal e tal e tal. Só falava e não mostrava as fotos". Outros se referem a conseqüências de algumas DST: “Tem gente que fica deficiente, cego, mudo, sei que lá, sei que lá... É de... Ah... Daquele trequeleco lá”.

As falas dos adolescentes nos dão pistas interessantes a respeito de uma abordagem singular para este público. Primeiramente, apontam para a necessidade de um processo discursivo pautado na linguagem falada: palavras, só falava e não mostrava as fotos pode sugerir uma demanda por parte dos mesmos do estabelecimento do diálogo. Outro aspecto é o caráter de objetividade que pode ser desprendido da seguinte afirmação: “o negócio é assim e tal, e tal, e tal".

Os adolescentes expressam uma demanda de mensagens associadas às experiências cotidianas:

Podia desenhar uma mulherzinha e um homenzinho... Tipo assim... Coloca tipo um balão assim com ela falando: Você tem alguma doença que é transmitida ou não? Ai o homenzinho vai e fala... Aí sei lá... Eu não tenho não. Então vai ter que usar isso, isso e isso pra... Não pegar doença. Aí se ele falar que não... Se tiver ele vai ter que falar que pra não pegar doença. Aí se ele não quiser, ele... Ele vai e não faz.

Ao ressignificar a mensagem a partir de seu lugar o sujeito está também traduzindo seu estado afetivo, uma vez que a linguagem escrita possibilita a criação de um espaço simbólico e estimula a imaginação do interlocutor. Uma linguagem visual que contemple personagens, cenários e vivências mais próximas do público receptor pode possibilitar a oportunidade de construir novos significados permitindo a maior compreensão de si mesmo (SCHALL, 2005).

\section{Considerações finais}

Considerando a interface entre saúde, educação e comunicação, percebe-se que, historicamente, os materiais educativos, as ações pedagógicas e as intervenções no âmbito da saúde - seja na elaboração ou transmissão das informações ou mensagens - são um reflexo da concepção de saúde/doença adotada. Segundo Stotz (1993), principalmente no campo da medicina preventiva, a forte influência do modelo biomédico terá ressonâncias nas ações educativas, que serão concebidas na lógica da educação instrutiva (passiva), pautadas na transmissão de conhecimento especializado, que a "gente detém e ensina" para uma "população leiga”, cujo saber é desvalorizado ou, simplesmente, desconsiderado 
(MEYER et al., 2006).

Como observado nos materiais aqui apresentados, a não consideração das especificidades e singularidades foi uma característica recorrente. No caso dos adolescentes, não faz sentido o planejamento de uma política em saúde ou práticas educativas amplas e generalistas, uma vez que não se pode falar em adolescentes no plural. Faz-se necessária a busca de estratégias conjuntas com os próprios adolescentes na tentativa de construir uma abordagem que possa ajudar, de alguma maneira, a melhorar o nível de informação e reflexão desse grupo, bem como ampliar o debate nas instâncias da família, educação e saúde.

É constante nos materiais descritos, a predominância de mensagens prescritivas, a descrição de métodos preventivos e um apelo ao enfoque cognitivo. As ações, materiais e estratégias educativas não devem se limitar ao aspecto meramente cognitivo. Devem possibilitar a instauração de um processo reflexivo que envolva os significados, sentimentos, medos e desejos dos receptores, que potencialize as ações de prevenção de doenças e promoção da saúde. Em nosso estudo, tanto os profissionais de saúde entrevistados, quanto os adolescentes sinalizaram para a necessidade de materiais educativos que sejam pensados de forma compartilhada e que reflitam as dúvidas, os anseios e as preocupações de públicos específicos.

Percebe-se também que a metade (sete dos materiais analisados) é desenvolvida pelo Governo Federal e os outros (oito dos materiais analisados) pela Prefeitura de BH/MG. Embora não tenham referência à equipe de criação, podese supor a contratação de agências de publicidade, aparentemente sem consultoria especializada e ancoragem em estudos com o público alvo. Uma participação mais efetiva e autônoma das secretarias municipais de saúde na elaboração de materiais educativos e de estratégias na área da promoção à saúde, com a participação dos conselhos municipais e envolvimento da comunidade, poderia contribuir para a formatação de ações e estratégias educativas mais específicas, norteadas pelas especificidades locais. Os centros de saúde precisam criar, recriar e pensar na efetividade de espaços mais atraentes e adequados que possam integrar a especificidade dos públicos.

Outro fator de extrema relevância é a necessidade de se articular as áreas de humanas e saúde para a produção de materiais informativos de qualidade, como manuais, cartilhas, folhetos, cartazes e vídeos que possam servir de instrumentos auxiliares valiosos, contribuindo para as políticas públicas visarem a promoção da saúde junto à população como um todo. Para que tais materiais possam servir como recursos educativos efetivos, faz-se necessário que eles sejam elaborados dentro de critérios interdisciplinares, compatíveis com a temática e a complexidade do seu público (LUZ et al., 2003).

O envolvimento da comunidade (crianças, mulheres, adolescentes etc.) potencializaria a reflexão e a apropriação pelos indivíduos do cuidado com a saúde. É válido destacar que a política do Sistema Único de Saúde (SUS) com base no princípio da descentralização e participação comunitária poderia ancorar tal perspectiva. É preciso refletir e discutir a respeito da participação individual e coletiva não apenas como dever, mas, antes, como direito.

$\mathrm{O}$ estudo de georreferenciamento revela que $24 \%$ dos nascidos vivos na Vila Cafezal, no ano de 2005, são filhos de mães adolescentes (NOGUEIRA et al., 2009). Tal fato nos faz pensar na elaboração de materiais educativos que contemplem a realidade local e possam instrumentalizar espaços de reflexão acerca do fenômeno da gravidez na adolescência. $\mathrm{O}$ uso do preservativo não deve estar associado apenas à prevenção de DST/AIDS, mas deve também contemplar e abrir espaços para a reflexão da necessidade de práticas sexuais protegidas contra uma gravidez não planejada. Em uma realidade com altas taxas de maternidade na adolescência, o único material que está voltado à temática refere-se ao álbum de planejamento familiar. No entanto, questiona-se a adequabilidade de tal material para o público adolescente, uma vez que nessa fase da vida, embora ocorra o evento da maternidade e da paternidade, os adolescentes não "planejam" uma vida familiar.

Não se pode perder de vista que as políticas de intervenção devem incorporar aspectos da dimensão social e cultural das práticas cotidianas, uma vez que ao tomarem suas decisões, os indivíduos não se baseiam somente no cálculo racional mas, antes, são influenciados pelas condições materiais e simbólicas do contexto no qual estão inseridos. Acredita-se ser fundamental o conhecimento da realidade do público que se quer atingir, para saber com quais códigos de comunicação, de linguagem e de valores pode-se abordá-lo.

\section{Nota}

1. Projeto financiado pela Fapemig. Edital PPSUS Processo 1 17/05 e CNPq: Edital Saúde da Mulher - Processo 551264/2007-1. 


\section{Referências bibliográficas}

ABDUCH, C. Grupos operativos com adolescentes. Cadernos, juventude, saúde e desenvolvimento, v.1. Brasília, DF, agosto, 1999. 303 p.

AYRES, J. Repensando conceitos e práticas em saúde pública. In: PARKER, R. \& TERTO JÚNIOR, V. (Org.). Aprimorando o debate: respostas sociais frente à AIDS. Rio de Janeiro: ABIA, 2002. p. 12-9.

BARDIN, L. Análise de conteúdo. Lisboa: Edições 70,1977

BARROS, C.R.P.; MATHIAS, C.R.J.C.; CATRO, D.M.F; OLIVEIRA， F.R.R.M.; GONCALVES, F.N.; MESSIAS, J.A.S.; COROMACK, L.M.F; MEIRELLES, Z.V. Catálogo Projeto Prisma Região Sudeste. Rio de Janeiro: Núcleo de Estudos de Saúde do Adolescente (NESA)/Uerj. 1999.

COSTA, J.F. O referente da identidade homossexual. In: PARKER, R.; BARBOSA, M. (Org.) Sexualidade Brasileiras. Rio de Janeiro: Editora Relume-Dumará/Associação Brasileira Interdisciplinar de AIDS/Instituto de Medicina Social, Uerj, 1996, p. 63-89.

DEBUS, M. Handbook for excellence in the investigation through focal groups. Washington, D.C, Heahth Com, 1994, 97 p.

FAUSTO NETO, A. Percepções acerca dos campos de saúde e da comunicação. In: PITTA, A.M.R. (Org.) Saúde e Comunicação: Visibilidade e Silêncios. São Paulo: Editora Hucitec/Rio de Janeiro: Abrasco, 1995. p. 267-94.

FREIRE, P. Ação cultural para a liberdade e outros escritos. Rio de Janeiro: Paz e Terra, 1987.

IBGE-INSTITUTOBRASILEIRODEGEOGRAFIA E ESTATÍSTICA. Censo demográfico. Brasília: IBGE, 2003. Disponível em: http://www.ibge.gov. br/. Acesso em: 10 dez. 2004

KELLY-SANTOS, A.; ROZEMBERG, B. Comunicação por impressos na saúde do trabalhador: a perspectiva das instâncias públicas. Ciência Saúde Coletiva 2005, v. 10, n. 4, p. 929-38.

L'ABBATE, S. Educação em Saúde: Uma Nova Abordagem. Cadernos de Saúde Pública, 1994. v. 10, n. 4 , p. $481-90$

LUZ, M.P.; PIMENTA, D.N.; RABELLO, A.; SCHALL, V.T. Avaliação de material informativo sobre leishmanioses distribuído no Brasil: critérios e subsídios para a elaboração e o aperfeiçoamento de materiais educativos para a saúde. Cadernos de Saúde Pública, 2003, v. 19, n. 2, p. 561-9.

MEYER, D.E.E; MELLO, D.F; VALADAO M.M. "Você aprende. A gente ensina?": interrogando relações entre educação e saúde desde a perspectiva da vulnerabilidade. Cadernos de Saúde Pública, 2006, v. 22, n. 6.

MONTEIRO, S.S.; VARGAS, E.P. Educação, comunicação e tecnologia educacional: interfaces com o campo da saúde. Rio de Janeiro: Editora Fiocruz, 2006.

NOGUEIRA, M.J. Sexualidade e gênero na adolescência: uma perspectiva educacional. Tese de Doutorado. Fundação Oswaldo Cruz, Rio de Janeiro, 2008.

NOGUEIRA, M.J.; SILVA, B.F.A.; BARCELOS, S.M.; SCHALL, V.T. Análise da Distribuição Espacial da Gravidez Adolescente no Município de Belo Horizonte - MG. Revista Brasileira de Epidemiologia, São Paulo, set. 2009, vol. 12, n. 3.

PIMENTA, D.N.; LEANDRO, A.; SCHALL, V.T. A estética do grotesco e a produção audiovisual para a educação e saúde: segregação ou empatia? O caso das leishmanioses no Brasil. Cadernos de Saúde Pública, 2007, v. 23, n. 5, p. 1161-71.

QUERÈ, L. De um modelo epistemológico da comunicação a um modelo praxeológico. Tradução de Westin, V. L. e Lamounier, L. Campinas: Ed. Mimeo, 1991.

ROZEMBERG, B.; SILVA, A.P.P; SILVA, P.R.V. Impressos hospitalares e a dinâmica de construção de seus sentidos: $\mathrm{O}$ ponto de vista dos profissionais de saúde. Cadernos de Saúde Pública, 2002, v.18, n.6, p.1685-94

SANTOS, P.L. Representações sobre o comportamento de leitura de crianças e adolescentes. Dissertação de Mestrado; Programa de Pós-Graduação em Educação, UFSCar; São Carlos, 1993.

SCHALL, V.T. Saúde e afetividade na infância: o que as crianças revelam e a sua importância na escola. Tese de Doutorado. PUC Minas, 1996.

SCHALL, V.T. Histórias, jogos e brincadeiras: alternativas lúdicas para crianças e adolescentes sobre saúde e ambiente. In: MASSARANI, L. O pequeno cientista amador. Rio de Janeiro: Editora Fiocruz, 2005, p.10-21. 
SINASC - Sistema Nacional de Informações Sobre Nascidos Vivos. Informações de saúde: nascidos vivos. Brasília: SINASC, 2004. Disponível em: (http://tabnet.datasus.gov.br/cgi/deftohtm. exe?sinasc/cnv/nvmg.def)

STOTZ, E.N. Enfoques sobre educação e saúde. In: VALLA, V.V.; STOTZ, E.N.; (Org.), Participação popular, educação e saúde: teoria e prática. Rio de Janeiro: Relume-Dumará; 1993.

WHO. Strengthening implementation of the global strategy for dengue fever / dengue haemorrhagic fever; 2008. Disponível em:

(http://www.who.int/csr/resources/publications/ dengue/WHO_CDS_D_EN_IC_2000_1/en/print. html).

VARGAS, E. P.; SIQUEIRA, V.H.F. Sexualidade e corpo: o olhar do sujeito através das imagens em vídeo. Cadernos de Saúde Pública, 1999, v.15(Sup.2), p. 69-83.

VASCONCELOS, E.M. 1999. Educação popular e a atenção à saúde da família. São Paulo: Editora Hucitec.

VASCONCELLOS-SILVA, P.R.; RIVERA, F.J.U.; ROZEMBERG, B. Próteses de comunicação e alinhamento comportamental sobre impressos hospitalares. Revista Saúde Pública, São Paulo, 2003, v. 4, n. 37, p. 531-42.

VILLA, E. A prática educativa no cotidiano do trabalho do profissional. In: GAZZINELI, M.F.; dos REIS, D.C.; MARQUES, R. (Org.), Educação em saúde: teoria, método e imaginação. Belo Horizonte: Editora UFMG, 2006.

\section{Sobre os autores}

\section{Maria José Nogueira}

Maria José Nogueira possui graduação e mestrado em Sociologia pela Universidade Federal de Minas Gerais $(1996,2003)$ e doutorado em Ciências da Saúde pelo Centro de Pesquisa René Rachou/Fundação Oswaldo Cruz (2008). Atualmente é pesquisadora do Centro de Pesquisa René Rachou/Fundação Oswaldo Cruz integrando a equipe de pesquisa em sexualidade, adolescência e promoção da saúde do Laboratório de Educação em Saúde. É professora colaboradora do programa de pós-graduação em Ciências da Saúde na mesma instituição. Atua principalmente nos seguintes temas: medicina social, adolescência, materiais educativos, gênero, promoção da saúde.

\section{Celina Maria Modena}

Celina Maria Modena possui graduação em Medicina Veterinária pela Universidade Federal do Rio Grande do Sul (1977), graduação em Psicologia e mestrado em Medicina Veterinária pela Universidade Federal de Minas Gerais $(2003,1981)$ e doutorado em Ciências pela Universidade Federal Rural do Rio de Janeiro (1989) e pós-doutorado em Saúde Coletiva pela Fundação Oswaldo Cruz. Tem experiência na área de Saúde Coletiva, com ênfase em Educação em Saúde, atuando principalmente nos seguintes temas: epidemiologia, saúde coletiva, psicologia social, representação social em saúde, determinantes sociais dos agravos em saúde e informação, educação e comunicação em saúde. 